\title{
Editorial
}

\section{Aborto terapéutico y ética científica}

La amplia confusión que hay en los medios de difusión, tanto nacionales como internacionales, sobre el aborto terapéutico me motiva a escribir este artículo.

También la Ética Médica e incluso la Bioética (1) no parecen haber incorporado una gran cantidad de conocimiento sobre la naturaleza humana adquirido recientemente en materia de genómica y biología de la reproducción, sea por ignorancia, sea por refractariedad o prejuicio sobre el conocimiento científico, sea por una posición filosófica que establece que la ciencia sólo puede aportar datos, pero el análisis válido sólo puede darlo la racionalidad (sin establecer siquiera qué es la racionalidad) filosófica. Tal confusión puede disiparse completamente con la ciencia y este nuevo conocimiento incluirse desde una perspectiva de Ética Científica (2), de allí que, este artículo me resulta obligatorio. Desafortunadamente la definición de aborto es distinta para el lego, para las leyes en los diferentes países y estados, en algunos ámbitos científicos, éticos, bioéticos, filosóficos y teológicos. La Real Academia Española de la Lengua define "abortar: dicho de la hembra, interrumpir en forma natural o provocada, el desarrollo del feto durante el embarazo" (3). En embriología se define como la interrupción del embarazo antes de que el feto sea viable "ex útero" (4). De inmediato surgen problemas con estas definiciones. ¿Es aborto interrumpir el embarazo en el estado de embrión? ¿Es aborto interrumpir el embarazo cuando el feto es viable, por ejemplo a los 6,5 meses? Según la lengua castellana sí, según la embriología no; en clínica se hablaría de un parto prematuro. ¿Es aborto interrumpir el embarazo cuando el feto no es viable ni "in útero" ni "ex útero"? ¿Es aborto interrumpir el embarazo de un ser que no tiene sistema nervioso (o cualquier sistema orgánico) funcional humano o no es un ser humano? Ahora tenemos un problema mayor ¿qué es un ser humano? Y como si fuera poco ¿desde cuándo un ser humano es individuo humano?
Las definiciones filosóficas como "animal racional" o "animal inteligente" son falsas y no pueden ayudarnos, puesto que han sido refutadas al encontrar que los animales son, en algunos aspectos, más racionales e inteligentes que el ser humano. Además, racionalidad no tiene una precisión científica y no puede ponerse a prueba porque carece de operacionalidad no ambigua. Hegel la define como la divinidad misma (5). Para la Biología, ser humano es un proceso que surge de la interacción del genoma de Homo sapiens con sus circunstancias o medio ambiente. Esta definición es más bien una noción abierta operacional y puede ser sometida a prueba de hipótesis factual y formal; está cimentada en las tres grandes teorías de la Biología: celular, de la herencia y de la evolución (6).

Es una condición necesaria, pero aun no suficiente para precisar el desarrollo de un ser humano, como veremos. Otro punto semántico conflictivo es el estado de embarazo. Por convención se ha aceptado que, para que haya embarazo es necesario que el embrión esté implantado, proceso que ocurre al día $6^{\circ}$ postconcepcional (4). Luego no podría (convencionalmente) denominarse aborto matar a un cigoto humano o impedir a un embrión implantarse. También hay discrepancias en el mundo médico y bioético por el inicio del estado de embrión; para algunos es desde la concepción (embrión unicelular), desde el estado de mórula, desde la implantación, de la aparición del tubo neural u otras convenciones. Todas estas ambigüedades surgen porque se realizan convenciones sobre los estados embrionarios que suceden independientemente de las concepciones, racionalidades o convenciones humanas.

La Ética Científica no hace convenciones sobre procesos que pueden ser investigados científicamente y, si las hace "a priori" es porque toda convención sobre procesos la convierte en una proposición que se prueba como hipótesis con la metodología científica. Deja a la naturaleza que nos 
enseñe lo que ella es y en ese ser cuál es el comienzo de la individuación. Así la convención que el individuo humano empieza cuando el embrión se implanta en el útero, se refuta científicamente porque hay seres humanos que han nacido de gestaciones extrauterinas y porque el ornitorrinco, que es un mamífero (no hay implantación en esta especie), no tiene útero y se reproduce por huevos. Hemos demostrado científicamente que el único estado que resiste toda refutación como origen de la individualidad humana o no humana es la integración programática del citoplasma ovular con el material hereditario que alberga, en una unidad autónoma constituyendo el cigoto (7).

De acuerdo a este conocimiento demostrado (y no simplemente dato) el inicio de la duplicación del material hereditario en el estado de pronúcleo (8) sería el candidato óptimo para el inicio del embrión (unicelular en este caso). Este proceso es igualmente válido para los seres humanos obtenidos por clonación por transferencia nuclear, para la molas hidatidiformes $u$ otros seres generados por las concepciones humanas. Nos quedaremos con la definición de la Embriología, para desde ella hacer la reflexión ética - científica. Por caracteres bien establecidos se ha aceptado que la separación entre embrión y feto humano es en la décima semana desde la última menstruación, en el día 56 desde la concepción o en la $8^{\circ}$ semana de desarrollo (4), con todo, la variabilidad poblacional no ha sido establecida, por lo que no deja de tener algo de arbitrario. Entremos en Ética. Matar o poner en condiciones de muerte a un ser humano es un acto contrario a cualquier paradigma de Ética o Ética Médica. Si aceptamos que el ser humano es individuo de la especie desde su concepción, o sea, desde el estado de zigoto matarlo en cualquier estado es un homicidio. Matarlo será un ovicidio, embriocidio o feticidio. Si no aceptamos este conocimiento científico tendremos el problema de inconsistencia o incoherencia con la ciencia, además de tener que fijar un comienzo para el individuo que se tornará siempre convencional y, se le impondrá a la naturaleza arbitrariamente una condición sin sustento factual.

La ley chilena reconoce a la persona humana desde que respira autónomamente o se corta el cordón umbilical. Pero, persona no tiene un significado científico. La Constitución Política de la República de Chile (9) en su artículo 19 dice "La Constitución asegura a todas las personas: $1^{\circ} \mathrm{El}$ derecho a la vida y a la integridad física y psíquica de la persona. La ley protege la vida del que está por nacer". Desafortunadamente, continúa "La pena de muerte solo podrá establecerse por delito...", con lo que introduce el relativismo ético en un tema tan delicado como es el respeto a la vida y una confrontación irreductible entre la moral o ética ordinaria y la ley. El artículo único de la Ley $\mathrm{N}^{\circ} 18.826$ (15 de Septiembre de 1989) que reemplazó al artículo 119 del Código Sanitario dice "No podrá ejecutarse ninguna acción cuyo fin sea provocar un aborto". Queda claro una diferencia insuperable entre la Ética Científica y la Ética Filosófica (Filosofía Moral) o la Bioética. La persona entra en la Ética Científica como una noción de algunas posiciones Éticas, pero sin contenido factual. Ocurre lo mismo con el alma o espíritu, que los toma como una creencia de algunas posiciones especialmente las religiosas. Resulta que para el Hinduismo y el Budismo los animales tienen alma por lo que son personas, lo que es una noción errónea para el Judaísmo, Cristianismo e Islamismo. Más aún la racionalidad, intelectualidad o mente humanas son tan procesos materio-energéticos como la duplicación del ADN en el cigoto al estado de pronúcleos y por lo tanto no nos pueden ayudar a dirimir el problema. Si aceptamos que la substancia humana o personeidad no es materioenergética constituimos un dilema insoluble y forzadamente obligamos al interlocutor a vincularse a la posición espiritualista (10).

Una confusión ampliamente presente en muchos ambientes es entre aborto eugenésico y aborto terapéutico. Aborto eugenésico es la interrupción del embarazo con la intención de matar al embrión o feto, dado que presenta una anomalía genética valorada negativamente por la madre o las personas que pueden tomar esa decisión. Esto se realiza en muchos países del mundo ante el diagnóstico de síndrome de Down, talasemia, u otras anomalías cromosómicas o génicas puntuales del embrión o feto que puede realizarse durante la vida intrauterina. Nada tiene que ver el aborto terapéutico con el aborto eugenésico. El llamado aborto terapéutico es la interrupción del embarazo en un estado de inviabilidad del feto o embrión, dado que este embarazo está causando un deterioro grave de la salud de la madre, le puede causar daños severos e irreversibles que pueden producirle la muerte.

La intención del aborto terapéutico es eliminar la causa del daño de la salud de la madre y, en ningún caso es matar al producto de la concepción sea este humano o no humano. No hay ninguna duda tanto en Ética general como en Ética Médica, porque no hay alternativa: de intervenir se puede salvar al menos la vida de la madre, de no intervenir se morirá la madre y el producto de la concepción. Como para la Ética Científica los motivos o intenciones importan mucho de tal modo que cambian la naturaleza de las acciones (porque los motivos o intenciones humanas son hechos neuropsíquicos), el 
aborto terapéutico no existe en Ética Científica, ya que sería una contradicción y, esta acción debería llamarse "interrupción terapéutica del embarazo". Como se indicó, la situación en Ética Médica era conocida y estaba totalmente resuelta.

Ampliemos el panorama. Si el embarazo va a matar a la madre y el feto o embrión son inviables en ese estado, ambos van a morir si no se interrumpe el embarazo. Luego, por lógica y ética elementales, la interrupción del embarazo al menos tiene una probabilidad alta de salvar a la madre (en las condiciones actuales de intervención) y en ese caso moriría sólo el feto o embrión, pero no habría la intención de matarlo. Curiosamente, distinguidos bioeticistas consideran que "El aborto terapéutico carece prácticamente, en la actualidad, de significado real. No es problema médico, ni por lo tanto tampoco jurídico o moral" (1). La realidad está muy lejos de esta opinión, al menos en los países menos tecnificados.

Hay varias situaciones que continúan siendo indicación del "aborto terapéutico". Pero antes de referirnos a ellas debemos aclarar la semántica en forma inambigua. Hemos visto que si no hay intención de matar al ser humano en gestación no debería llamarse "aborto". Pero es innegable que si no se tienen los recursos para continuar el desarrollo del feto o embrión "ex útero", una interrupción del embarazo cuando este ser no es viable es conducente a su muerte. Luego aunque no se quiera matarlo se detiene su desarrollo y queda en condiciones de muerte.

Por eso continúo llamando a esta acción "aborto terapéutico" porque físicamente lo es. Algunos eticistas que valoran mucho la intención de las acciones insisten en llamarla "interrupción terapéutica del embarazo". El nombre no es trivial ya que en Chile, como se mostró, cualquier acción que lleve al aborto está prohibida. La postura detrás del nombre tampoco es irrelevante. Puede aparecer una intencionalidad de trivializar las acciones cambiándoles el nombre (solucionar los problemas por secretaría o por decreto de cambio de nombre) o simplemente un fariseismo que da una importancia grande al nombre pero no al fundamento, contenido o espíritu de las acciones. Por otra parte es necesario respetar lo que culturalmente ha sido consagrado por el uso tanto médico como del pueblo. De cambiar el nombre esto debería hacerse por toda la comunidad chilena empezando por la comunidad médica y, por ley reconocer que la interrupción terapéutica del embarazo no cae dentro de la prohibición de la Ley 18.826 (lo que va a contravenir el lenguaje común que no siempre acepta la intención como cambio sustantivo de las acciones). La otra forma es legislar especialmente para el "aborto terapéutico". Pasemos ahora a las indicaciones de aborto terapéutico. Hay condiciones del embarazo mismo:

I) La infección ovular. El producto de la concepción se infecta y esta infección trasciende a la madre en un estado del embarazo donde el embrión es inviable. Esto ocurre espontáneamente o más frecuentemente por intento de aborto en condiciones sépticas. Comúnmente llega la madre embarazada a un servicio de urgencia obstétrica, con fiebre sobre $40^{\circ}$ y frecuentemente con septicemia y shock séptico. Los segundos en la decisión son vitales. Normalmente por el grado de fiebre el feto ya está muerto o agoniza. El vaciamiento uterino es la única medida para salvar a la madre de secuelas graves o de la muerte. Esto ha ocurrido y ocurre por centenares de miles o millones al año en el mundo. El uso masivo de métodos de regulación de la natalidad, la educación y el aborto clandestino con técnicas asépticas han contribuido a disminuir esta patología.

II) El embarazo ectópico. El cigoto o embrión tienen una gran capacidad de inducir las condiciones de anidación que necesitan en cualquier tejido donde se implantan (argumento fuerte para su condición de autonomía y por lo tanto individuo humano). Pero sólo el útero está adaptado para producir un embarazo con altas probabilidades de llegar a término. Los embarazos tubarios, peritoneales o que comprometen órganos o tejidos, páncreas, riñones, intestinos y que raras veces pueden llegar a término (algunos peritoneales lo han hecho). El problema crítico es, a menudo, el compromiso de grandes vasos que puede llevar a hemorragia y a shock hipovolémico a la madre, en estado de inviabilidad "exorganon" del feto. La intervención quirúrgica tiene como objetivo la reparación de los vasos de la madre lo que lleva a la extracción del embrión o feto con su consecuente muerte.

III) La formación de una concepción anómala desde la fertilización. Hay muchos casos, pero aquí trataremos dos. La mola hidatidiforme que se produce frecuentemente por una fecundación normal por un espermio $X$ en un ovocito que luego pierde su núcleo. El espermio se endoduplica y constituye un cigoto con información paterna exclusiva. Tiene por lo tanto un genoma humano completo y un cariotipo humano normal 46, XX. Es necesario recordar que durante la espermatogénesis el material hereditario nuclear sufre el proceso de activación o desactivación génica (imprinting o programación molecular) y lo mismo pasa a los óvulos durante la ovogénesis. Este imprinting es distinto en ambos sexos de tal modo que los gametos tienen genomas funcionalmente complementarios. Un cigoto con material he- 
reditario exclusivo de la madre o del padre no logra constituir un embrión en mamíferos. El imprinting del padre es necesario para formar preferencialmente los anexos del embrión y es deficitario para formar al embrión propiamente tal, el de la madre preferencialmente participa en la formación del embrión pero es deficitario para formar anexos. Con todo ambos se necesitan para formar tanto anexos como embrión. La mola constituye un tejido preferentemente anexial arracimado sin forma humana embrionaria. Se maligniza frecuentemente (coriocarcinoma) y origina precozmente metástasis en la madre. La mola ha sido considerada como no humana por la clínica médica y dada su malignidad se hacen esfuerzos para detectarla lo más precozmente y proceder al "aborto molar" que nadie llama aborto sino vaciamiento uterino por embarazo molar. La mola "masculina" 46 YY es menos dañina ya que no es viable. Un caso más complejo es el triploide, producido frecuentemente por la fecundación de un ovocito por dos espermios y menos frecuentemente por la fecundación por un espermio de un ovocito con dos núcleos (no expulsión de algún corpúsculo polar). Se produce (cuando sobrevive al primer mes) una "mola embrionada" con tejido molar y un embrión anómalo que puede tener partes de su anatomía molar. El embrión es anatomopatológicamente anómalo. Todos sus tejidos y células muestran anomalías severas. Aunque no hay unanimidad, creo que hay suficientes anomalías para considerar al triploide (tetraploide y otros emergidos por fecundaciones anómalas) como un ser no humano. Cromosómicamente en su estructura es aún más anómalo que la mola. Su tejido molar es también invasivo y, por esto debería vaciarse el útero inmediatamente hecho el diagnóstico. Hay numerosos casos de anomalías cromosómicas que no es posible tratar por extensión del trabajo. Hay situaciones no directamente involucradas en el embarazo.

IV) Las insuficiencias sistémicas u orgánicas desencadenadas por el embarazo. Las más frecuentes son la cardiaca, la respiratoria, la endocrina y la renal. Hay también la insuficiencia de la regulación de la autoinmunidad que lleva al desencadenamiento o agravamiento de una enfermedad autoinmune en la madre; un ejemplo es el penfigoide del embarazo que afortunadamente sucede con severidad en etapas tardías y una terapia médica prolonga el embarazo hasta la viabilidad del feto $(11,12)$. Hay enfermedades generales como la miastenia gravis (también autoinmune) que se agravan con el embarazo; una paciente con esta enfermedad y penfigoide del embarazo eligió el aborto terapéutico (13).
¿Quién toma la decisión del "aborto terapéutico?". Tomando como invariante al paciente que es la mujer embarazada cuando está consciente, examinaré los miembros del equipo de profesionales tratantes. Las variables que deben tomarse en cuenta para la decisión son principalmente y críticamente tres. El compromiso vital o de la salud de la paciente embarazada y la inminencia de su muerte. El estado del proceso gestacional, el diagnóstico de embrión o feto humano (o no humano), su carácter de invasivo o su peligrosidad de continuar en la embarazada. La viabilidad del embrión o feto humano con las técnicas con que se cuenta para hacerlo vivir ex útero. El único que puede conocer e integrar mejor estas variables es el médico tratante o responsable (que en general es un obstetra) con el equipo de profesionales que ha contribuido a los diagnósticos y a la evaluación de las variables vitales de la paciente. Estas variables necesitan de una evaluación fina y de un cálculo clínico que sólo los que están directamente vinculado a la paciente pueden hacer. De allí que es mi convicción que la decisión de proponer el "aborto terapéutico" debe tomarla el médico tratante o el equipo de salud directamente a cargo de la paciente con la ética médica y criterio comunes. Excepcionalmente (como en el caso de miastenia gravis y penfigoide del embarazo) deberían participar los Comités de Ética o Bioética de los hospitales. Es necesario recuperar y dar crédito a la Ética Médica habitual que tiene en estos casos los recursos para lograr la prescripción correcta.

Dr. Carlos Valenzuela Y. Profesor de Genética, Ética y Epistemología. Profesor Titular, Facultad de Medicina, Universidad de Chile.

Nota: una versión más acabada está en: Valenzuela CY. Ética científica del aborto terapéutico. Rev Med Chile 2003;131(5):562-8.

\section{REFERENCIAS}

1. Marciano Vidal. Bioética. Estudios de bioética racional. Tecnos. Madrid, 1989.

2. Valenzuela CY. Ética científica y embriones congelados Rev Méd Chile 2001;129: 561-8.

3. Diccionario de la Lengua Española.

4. Embryology. O'RAHILLY R, MÜLLER F. Human Embryology \& Teratology, 2nd Ed. New York, NY: WileyLiss, 1996.

5. Hegel GWF. Vie de Jesus. Paris. Editions D'aujourd hui, 1928.

6. Valenzuela CY. Ética científica del origen humano. Rev Méd Chile 1997;125:701-5.

7. Valenzuela CY. Comienzo ontogénico del indivi- 
duo humano desde su genoma. Rev Méd Chile 2001;129:441-6.

8. Shostak S. Embryology. Harper and Row, New York, USA, 1991.

9. Constitución Política de la República de Chile.

10. Besio MR. Inicio de la vida humana. La necesidad de una reflexión filosófica. Rev Méd Chile 1997;125:1494-9.

11. Amato L, Coronella G, Berti S, et al. Successful treatment with doxycycline and nicotinamide of two cases of persistent pemphigoid gestationis. J Dermatolog Treat 2002;13:143-6.

12. Shimanovich I, Skrobek C, Rose C, et al. Pemphigoid gestationis with predominant involvement of oral mucous membranes and IgA autoantibodies targeting the C-terminus of BP180. J Am Acad Dermatol 2002;47:780-4.

13. Kaufman AJ., Ahmed AR., Kaplan RP. Pemphigus, myasthenia gravis, and pregnancy. J Am Acad Dermatol 1988;19(2 Pt 2):414-8. 